\title{
Insulin-like growth factor 1 is related to the expression of plumage traits in a passerine species
}

\author{
Katharina Mahr ${ }^{1,2}$ (D) Orsolya Vincze ${ }^{3,4} \cdot$ Zsófia Tóth $^{1} \cdot$ Herbert Hoi $^{2} \cdot$ Ádám Z. Lendvai ${ }^{1,5}$ \\ Received: 8 October 2019 / Revised: 18 February 2020 / Accepted: 27 February 2020 / Published online: 10 March 2020 \\ (C) The Author(s) 2020
}

\begin{abstract}
Avian plumage colors and ornaments are excellent models to study the endocrine mechanisms linking sexually selected traits and individual parameters of quality and condition. Insulin-like growth factor 1 (IGF-1) is an evolutionarily highly conserved peptide hormone. Its regulatory role in cell proliferation and differentiation and its high sensitivity to the nutritional state of individuals suggest it as an interesting candidate, possibly providing a link between body condition and individual capacity to grow elaborated ornamental features. We investigated whether IGF-1 levels during molting correlate with the expression of multiple ornaments in a sexually dichromatic passerine species, the bearded reedling (Panurus biarmicus). We collected blood samples of males and females shortly before the molting completed and measured the size and colors of ornamental traits. Our results indicate that in males, structural plumage colors, the size of the melanin-based ornament (beard), and tail length are independent traits. IGF-1 levels are associated with the length of the tail and the expression of male structural plumage components (UV coloration), but not the melanin-based ornament. In females, plumage color and tail length were independent traits, which were not related to IGF-1 levels. To the best of our knowledge, this study provides the first evidence that IGF-1 could play a role in the development of secondary sexual characters in a bird species.
\end{abstract}

\section{Significance statement}

IGF-1 is an evolutionarily highly conserved peptide hormone, which recently entered the center stage of research enquiry in evolutionary biology. It is considered as one of the key factors shaping individual life histories, but little is known about its effects on sexually selected traits. We investigated whether IGF-1 levels during molting predict the elaboration of multiple ornamental plumage traits in male and female bearded reedlings (Panurus biarmicus). Our results indicate that higher IGF-1 levels had positive effects on male structural plumage colors and tail feather length. This is the first study, bringing indication for a potential role of IGF-1 in the expression of plumage ornaments in a bird species. Our findings suggest that IGF-1 might serve as an ideal candidate to study the mechanisms linking condition and the capacity to develop sexually selected ornaments.

Keywords Plumage coloration · Sexual selection · Physiology $\cdot$ IGF-1 · Condition

\section{Communicated by K. McGraw}

Electronic supplementary material The online version of this article (https://doi.org/10.1007/s00265-020-2821-6) contains supplementary material, which is available to authorized users.

Katharina Mahr

Katharina.Mahr@vetmeduni.ac.at

1 Department of Evolutionary Zoology and Human Biology, University of Debrecen, Debrecen, Hungary

2 Department of Interdisciplinary Life Sciences, Konrad Lorenz Institute of Ethology, University of Veterinary Medicine, Vienna, Austria
3 Evolutionary Ecology Group, Hungarian Department of Biology and Ecology, Babeș-Bolyai University, Cluj-Napoca, Romania

4 Department of Tisza Research, MTA Centre for Ecological Research, Debrecen, Hungary

5 Department of Geology, University of Babeș-Bolyai, Cluj-Napoca, Romania 


\section{Introduction}

The physiological processes shaping the relationships between showy ornaments and individual parameters of quality and condition have been investigated intensively over the past decades. In that respect, hormones and their pleiotropic effects present one of the key mechanisms, linking individual physiology and the capacity to develop elaborated sexually selected traits (Nolan et al. 1992; Peters et al. 2006; Roberts et al. 2009; Flatt and Heyland 2011; Laucht and Dale 2012; Hudson and Wilcoxen 2018). The best studied examples are androgens, which orchestrate the investment into behaviors related to reproduction and stimulate the growth of secondary sexual characters (Andrew 1969; Alonso-Alvarez 2001; Peters et al. 2006; Roberts et al. 2009; Flatt and Heyland 2011). Their effects, however, come along with costs, which result in the suppression of the immune system and an increase in oxidative stress, which force the bearer of an ornament into a tradeoff between the differential allocation of resources into ornamental features or self-maintenance (e.g., growth, immunecompetence) (Nolan et al. 1992; Ketterson and Nolan 1999; Hau 2007; Flatt and Heyland 2011). The capacity of individuals to cope with these trade-offs might constitute one of the key factors linking condition and ornament expression in many vertebrate species.

There is a phylogenetically ancient hormonal pathway, the insulin/insulin-like growth factor 1 (IGF-1), which has been less investigated than sex steroids but plays a crucial role in the mediation of life-history trade-offs (Zera and Harshman 2001; Barbieri et al. 2003; Harshman and Zera 2007; Sparkman et al. 2009; Dantzer and Swanson 2012; Shit et al. 2014). IGF-1 is an evolutionarily conserved polypeptide metabolic hormone, which serves as the main mediator of the growth hormone $(\mathrm{GH})$. Its expression is regulated along the hypothalamic-pituitary-somatotropic axis (HPS axis). After stimulation (through $\mathrm{GH}$ ) of the production in the liver, IGF-1 is released to the bloodstream. It is an organism-wide integrator regulating development, growth, and reproduction and moreover life span in vertebrates by stimulating cell proliferation, migration, and differentiation and protein synthesis in almost every cell of the body (Liu et al. 1993; Doublier et al. 2000; Dantzer and Swanson 2012). Stress, infection, and nutritional status (e.g., malnutrition) affect IGF-1 secretion and its effects on individual physiology (Dantzer and Swanson 2012; Emlen et al. 2012; Lodjak et al. 2016; Tóth et al. 2018). There is a compelling body of evidence that environmental factors and external stimuli (Ciucci et al. 2007), as for example resource limitation or ambient temperature (Gabillard et al. 2003), have effects of IGF-1 expression and secretion in vertebrates (Dantzer and Swanson 2012). The high responsiveness of the IGF-1 system towards external stimuli and its regulatory functions give it an important role in shaping life history traits, which also involve the development of sexually selected characters (Suttie et al. 1985; Ditchkoff et al. 2001; Emlen et al. 2012; Lewin et al. 2017).

We propose that the capacity of IGF- 1 in mediating the effects of environmental factors on individual life-history traits makes it an interesting candidate to link parameters of body condition and the expression of avian plumage ornaments. Ornamental plumage traits appear in different forms like, for example, elongated feather structures, striking colors, or ornamental patterns (Andersson 1994b; Andersson et al. 2002; Hill and McGraw 2006b; Hill and McGraw 2006a; LaFountain et al. 2015; Roulin 2016). Despite their remarkable diversity, they share the same characteristics: they serve as "quality indicators" (phenotypic and genetic) and hence correlate with individual access to resources and future reproductive success (Andersson 1994a; McGraw et al. 2002; Delhey and Kempenaers 2006; Hill and McGraw 2006a, b; Jacot and Kempenaers 2006; McGlothlin et al. 2007; Murphy and Pham 2012; Musgrove and Wiebe 2016; Hudson and Wilcoxen 2018). Intensity, size, and elaboration of plumage colors and ornaments are determined during molt, and certain types of ornamentation are regarded as costly to produce. The development of plumage colors (e.g., carotenoid-based colors) and feather structures (e.g., tail length), for example, was shown to be negatively affected by malnutrition or physiological stress, which makes these ornamental traits highly sensitive towards parameters of condition during molting (Svensson and Merilä 1996; McGraw et al. 2002; Loyau et al. 2005; Griggio et al. 2009; Hudson and Wilcoxen 2018). The renewal and growth of feathers is a long and energydemanding process, which requires major changes in the metabolic rate, a vast increase in cell proliferation rate, cell differentiation, and body protein synthesis (Kuenzel 2003). Considering that IGF-1 (i) regulates all of the aforementioned processes, which are tightly linked to the physiological requirements of molting, (ii) is highly sensitive towards the nutritional status (Gunnell et al. 2003; Mazzuco et al. 2005; Clemmons 2012; Dantzer and Swanson 2012), and (iii) signals the availability of resources (Bartke et al. 2003; Mattson et al. 2004), it might also affect the individual capacity to grow condition-dependent ornamental features. Whereas the role of IGF-1 in growth and development of avian species has been investigated (McMurtry et al. 1997; Beccavin et al. 2001; Lodjak et al. 2014, 2016, 2017), to the best of our knowledge, the relationship between plumage ornaments, body condition, and IGF-1 concentrations during the molt has yet not been studied.

Conspecifics often evaluate individuals based on several cues and signals, rather than one single trait, and in many species, males and females display multiple ornaments (Andersson 1994a; Andersson et al. 2002; Candolin 2003; Alonso et al. 2005; Mahr et al. 2016). These different traits can provide redundant information and/or amplify a signal, provide different information, or have no further informational content ("unreliable" signal) (Andersson et al. 2002; Candolin 2003; Ornelas et al. 2009; Griggio et al. 2016). Therefore, in 
order to gain insight into the role of IGF-1 as a possible link between parameters of condition and ornament expressions, we investigated multiple ornamental plumage traits. Our model species is a free-living European passerine, the bearded reedling (Panurus biarmicus). While displaying a strong sexual dichromatism, males and females carry multiple ornamental features (Surmacki et al. 2015), with different characteristics, which might affect the information these traits convey to receivers (Hill and McGraw 2006a) (Fig. 1). Male bearded reedlings display a distinct melanin-based ornament, the black beard, which is an honest signal and underlies inter- and intrasexual selection. It was shown, for example, that males with larger beards are more dominant and, further, females display a preference for males with a more elaborated beard (Hoi and Griggio 2008). Previous studies on this species also demonstrated that the length of the tail is a sexually selected trait in males and females (Romero-Pujante et al. 2002; Peiró et al. 2006; Hoi and Griggio 2008; Griggio et al. 2016). Moreover, males are characterized by a conspicuous blue head and a rose/pink flank region and both males and females possess an achromatic bright chin (Fig. 1). These plumage regions

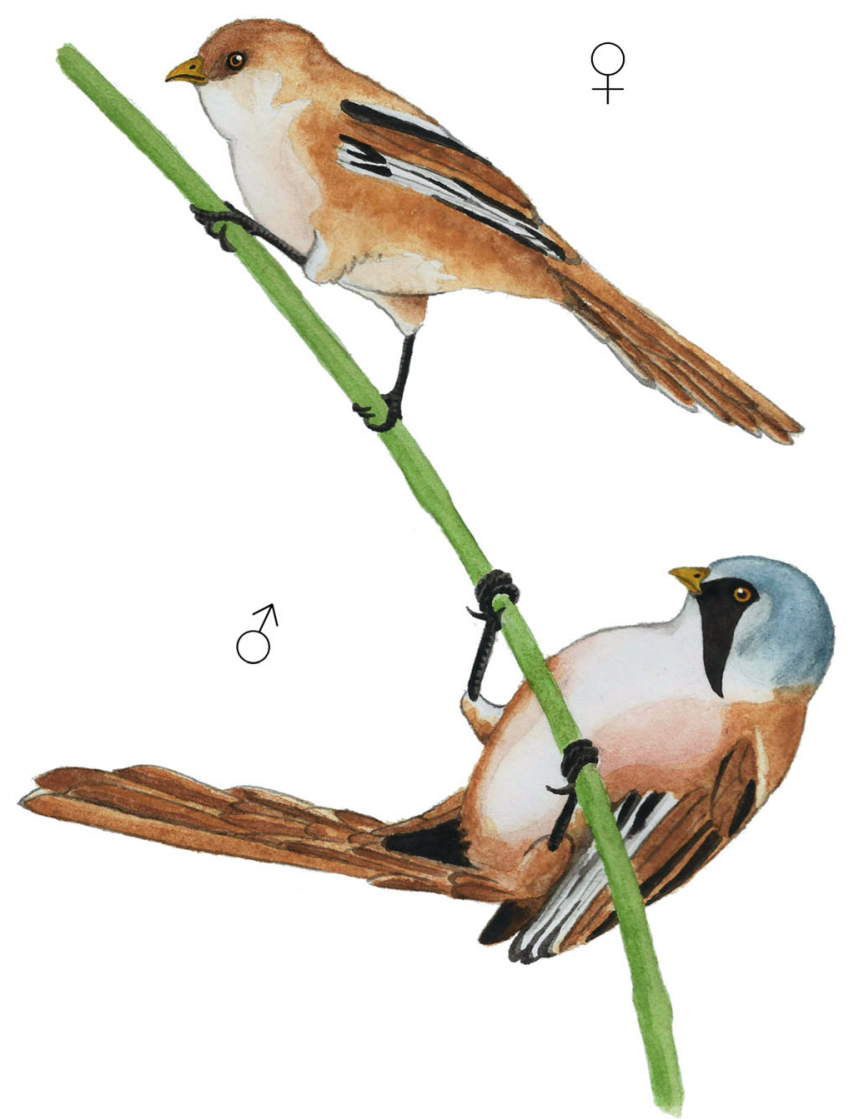

Fig. 1 Female and male bearded reedlings display a strong sexual dichromatism. The conspicuous blue head and rose flank region of the males as well as the achromatic bright chin reflect in the UV range (original artwork provided by G. Rédai, Department of Evolutionary Zoology and Human Biology, University of Debrecen, Debrecen, Hungary) are characterized by reflection in the UV range (Fig. 2), which indicates the presence of structural plumage components (Osorio and Ham 2002; Mays et al. 2004; Shawkey and Hill 2005). Structural plumage colors are the result of keratin structures and air spaces embedded in the spongy medullary layer of the feather (Hill and McGraw 2006a, b). Their regularity, which is highly sensitive towards parameters of individual condition during the molt, predicts the degree of UV reflectance in the feathers (Keyser and Hill 1999; Griggio et al. 2009, 2010b). We therefore examined structural plumage components, by measuring UV chroma in addition to the melanin-based plumage colors of the body feathers in both sexes.

In order to explore whether IGF-1 serves as possible link between body condition and plumage traits, we captured freeliving bearded reedlings at the final stage of their molt and measured their baseline IGF-1 levels. The timing of the study was based on findings in other species, showing that IGF-1 secretion increases strongly towards the end of the molt (Mazzuco et al. 2005) and circulating levels are significantly higher in comparison to non-molted birds. We brought the birds into a spacious aviary under semi-natural conditions, and after completion of the molt, we measured plumage traits in both sexes. We then tested for a relationship between the multiple ornamental traits and parameters of body size and condition (Hoi and Griggio 2008; Griggio et al. 2016) and investigated whether baseline IGF-1 levels collected during late molting stages predicted the expression of plumage characteristics. We expected that ornamental features, which are sensitive towards body condition during molt, would be related to condition parameters. If IGF-1 increases individual capacity to invest into the development of sexually selected characters, we expected to observe a positive relationship between IGF-1 plasma concentrations and parameters of plumage quality.

\section{Methods}

\section{General methods}

Free-living bearded reedlings were captured at Lake Neusiedl (47 46' 10.5" N, $16^{\circ} 45^{\prime} 20.1^{\prime \prime}$ E, Burgenland, Austria) in September and October 2016. During this time of the year, bearded reedlings have almost finished their molt and have moved through the area in large flocks $(\mathrm{HH}, \mathrm{OV}$, and $\mathrm{KM}$ personal observations).

Mist netting was conducted between 0700 and 1600 . Immediately after the capture, we collected blood samples (70-140 $\mu \mathrm{l})$ by puncturing the brachial vein. The blood samples were drawn within $3 \mathrm{~min}($ mean $\pm \mathrm{SD}, 138.65 \pm 59.67 \mathrm{~s})$ from the time when the bird hit the net, and therefore, these samples are considered as baseline measurements (Wingfield and Romero 2001; Romero and Reed 2005; Tóth et al. 2018). Immediately after sampling, we transferred the blood into 0.5 - 
Head
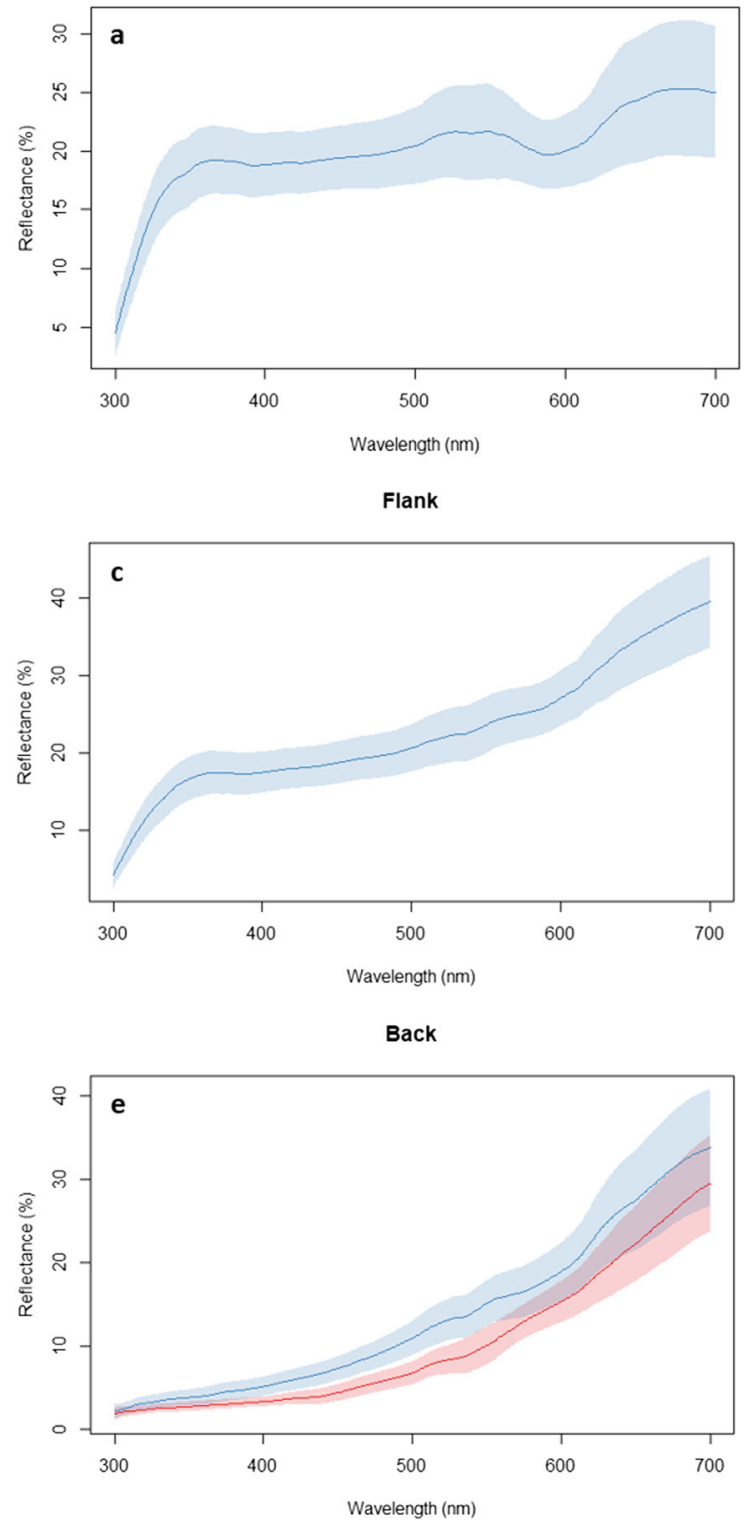

Fig. 2 The average spectral curves based on 23 male (blue) and 20 female (red) bearded reedlings. Note that the head, flank, chin, and cheek (panels a-d) indicate reflectance in the UV range (320-400 nm), while the brown

$\mathrm{ml}$ microcentrifuge tubes, which were stored in a cooling box until further processing in the laboratory. The plasma was separated from red blood cells, by centrifuging the sample for $5 \mathrm{~min}$ at $2000 \mathrm{~g}$ and removing the plasma with a Hamilton syringe $(50 \mu \mathrm{l})$. After each sample, the Hamilton syringe was flushed 5 times by drawing up $50 \mu$ of distilled water. We stored the samples in $\mathrm{a}-20^{\circ} \mathrm{C}$ freezer until they were assayed for IGF-1 by enzyme-linked immunosorbent assay (ELISA; see details below).

All birds were banded with a unique combination of darvic color rings. Only individuals in adult plumage, which have molted more than two thirds of their plumage, entered the study ( $n=42$ birds; 11 birds were excluded at this point); the
Chin
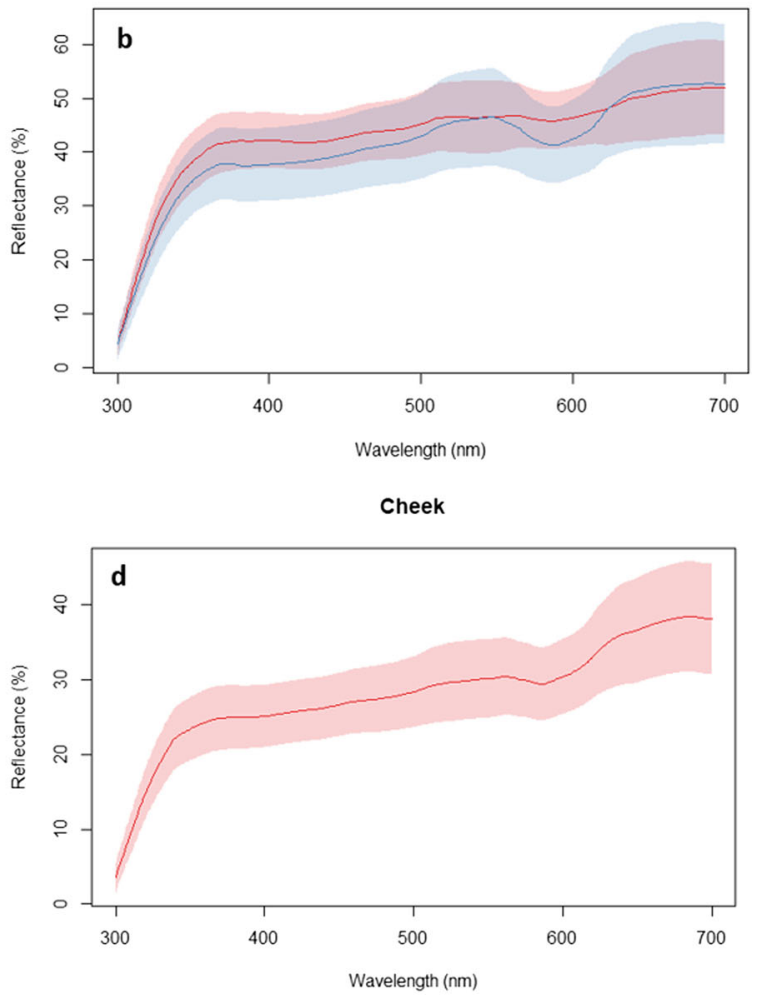

coloration of the back (panel e) does not reflect in the UV range. The lines show the average reflectance, and the shaded areas show the corresponding $95 \%$ confidence intervals

stage of the molting was estimated by looking at the number of feather quills in proportion to newly grown feathers at the given time (following the protocol provided by the Vogelwarte Radolfzell). The sex was determined by plumage coloration (Svensson 1992). Subsequently, we measured body mass (to the nearest $0.01 \mathrm{~g}$ ), tarsus length (to the nearest $0.01 \mathrm{~mm}$ ), and tail length (to the nearest $0.5 \mathrm{~mm}$ ). Immediately after the measurements, we transferred the birds to individual cages. Bearded reedlings usually adapt to captive conditions very fast, but some individuals may be unusually stressed by the captive conditions. This was tested by providing each bird with 5 mealworms, and after $2 \mathrm{~h}$, we counted the remaining mealworms. Only birds that resumed feeding 
within $2 \mathrm{~h}$ after capture were regarded as capable to cope with the captive situation ( $80 \%$ of all birds tested), and were transferred to the housing facilities of the Konrad Lorenz Institute of Ethology, University of Veterinary Medicine, Vienna, Austria. The birds were kept in a mixed-sex flock in a large outdoor aviary $(10 \times 5 \times 4 \mathrm{~m})$, under natural light regime and conditions simulating their natural environment. The aviary contained dense vegetation of naturally growing Sambucus nigra; we also provided reed bundles and papyrus plants (Cyperus papyrus). The birds received water, a mixed diet of commercial insectivorous food (protein mash, apples, quark, egg, carrots), seeds (canary seeds, millet, hemp seeds), and mealworms ad libitum. Taking the birds into captivity was necessary because recapturing all the sampled birds in the field, once they completed molting, would not have been possible. Furthermore, all individuals finished molting under the same standardized conditions, although effects of captivity on wild-caught birds cannot be excluded.

\section{Characterization of plumage traits}

We characterized plumage traits in male and female bearded reedlings after all individuals had finished molting. To determine the end of the molt, we controlled the progress of the molt weekly; after 6 weeks, no growing feather quills were visible. The freshly molted plumage coloration was measured using a USB-2000 spectrometer and a DHS-2000-FHS deuterium halogen lamp, connected through a bifurcated fiber-optic probe (Ocean Optics, Eerbeek, Netherlands). By fitting a black rubber cylinder on the top of the probe, we minimized disturbance by outer light sources and ensured a standardized distance and angle $\left(90^{\circ}\right)$. Prior to each measurement, the spectrophotometer was recalibrated. For the calibration of white, we used a white standard (Avantes, Eerbeek, Netherlands); for black, we removed the probe from the light source and closed the cap of the plug (Griggio et al. 2009; Mahr et al. 2012, 2016).

We obtained 3 measurements from distinct regions of the plumage in males (head, flank, back, chin) and females (chin, cheek, back) (Fig. 1). Based on the obtained spectral curves (Fig. 2) and the literature (McGraw et al. 2005; Hill and McGraw 2006a, b), we decided to focus on two standard descriptors of reflectance variables, which were generated from the raw reflectance data: brightness and UV chroma. We used brightness to estimate the degree of melanization of the brown back of males and females (Fig. 2), which we calculated as the average percent reflectance in the 320-700-nm range. Brightness was previously shown to reflect the melanin content of plumage features, with low brightness indicating higher pigmentation (McGraw et al. 2005). The spectral curves of the head, flank, and chin of males and the chin and cheek of females, respectively, revealed the presence of plumage components facilitating the reflectance in the UV range (here defined between 320 and $400 \mathrm{~nm}$ ) (Fig. 2). In order to quantify UV reflectance of the feathers, we calculated UV chroma, which is the proportion of reflectance in the UV range compared to the total reflectance (320-700 nm) (Hill and McGraw 2006b; Griggio et al. 2010a; Mahr et al. 2012). Spectral measurements were restricted to a range between 320 and $700 \mathrm{~nm}$, which reflects the avian color vision spectrum (Hill and McGraw 2006b).

In addition to the colorimetric variables, we measured the tail length for both sexes and quantified the length of the black male beard, which were previously shown to be sexually selected traits in this species (Romero-Pujante et al. 2002; Hoi and Griggio 2008; Griggio et al. 2016). Tail length was measured using a ruler (to the nearest $0.5 \mathrm{~mm}$ ). To measure the beard length (to the nearest $0.01 \mathrm{~mm}$ ), three photographs (left/right side and front) of each male individual were taken by placing the birds in front of a millimeter paper at a standardized distance $(25 \mathrm{~cm})$ from the camera (Nikon D 60, Nikon Corporation, Tokyo, Japan) mounted on a tripod (Manfrotto, Vitec Imaging Solutions Spa, Cassola, Italy). All pictures were taken without a flash; to standardize conditions, the ambient light was only provided by artificial light under laboratory conditions. We used the software ImageJ (Rueden et al. 2017) to determine the beard length, by measuring a known distance on the millimeter paper as a scale $(10 \mathrm{~mm}$ on each picture) and calculating the distance between the lowest and highest point of the beard in millimeters. For the analyses, we calculated the average beard length (in mm). All measurements were conducted by the same person to minimize variation through measurement errors. To minimize observer bias, blinded methods were applied during all measurement procedures in the field and the laboratory and the subsequent analyses of the data.

\section{IGF-1 plasma concentrations}

Plasma IGF-1 levels were measured in duplicates by a competitive ELISA developed in our laboratory at University of Debrecen (AZL et al. unpublished data). Ninety-six-well NUNC microplates were coated overnight at $4{ }^{\circ} \mathrm{C}$ with $100 \mu \mathrm{l}$ of an antibody raised against IGF-1 in rabbits. The capture antibody was incubated for $2 \mathrm{~h}$ at room temperature $\left(24^{\circ} \mathrm{C}\right.$ ) with $20 \mu \mathrm{l}$ known concentrations (in serial dilutions starting at $500 \mathrm{ng} / \mathrm{ml}$ ) of synthetic chicken IGF-1 or $20 \mu \mathrm{l}$ of sample and $100 \mu$ biotinylated IGF-1. After incubation, the microplate was washed three times with $250 \mu$ of PBS buffer ( $8 \mathrm{~g} \mathrm{NaCl}, 0.2 \mathrm{~g} \mathrm{KCl}, 1.44 \mathrm{~g} \mathrm{Na}_{2} \mathrm{HPO}_{4}$, and $0.24 \mathrm{~g} \mathrm{KH}_{2} \mathrm{PO}_{4}$ in $1000 \mathrm{ml}$ ddH2O, pH 7.4) containing $0.025 \%$ Tween 20. After washing, $100 \mu \mathrm{l}$ of streptavidin-horseradish peroxidase conjugate was added to all wells and incubated at room temperature for $30 \mathrm{~min}$ during which the enzyme conjugate bind to the biotinylated IGF-1. The incubation was followed by another washing cycle (3 times), and then, $100 \mu$ of tetra-methylbenzidine was added to the wells and incubated at room 
temperature for $30 \mathrm{~min}$. The enzymatic reaction was stopped by adding $100 \mu \mathrm{l}$ of $1 \mathrm{M} \mathrm{H}_{2} \mathrm{SO}_{4}$, and optical density was measured at $450 \mathrm{~nm}$ (reference at $620 \mathrm{~nm}$ ). The calibration curve was fitted using a 4-parametric log-logistic curve, and concentrations of unknown samples were read off from this curve. We used a chicken plasma in quadruplicate to determine intra- and inter-assay coefficient of variation $(4.8 \%$ and $9.7 \%$ respectively). In this assay, we did not use any extraction protocol on our samples. This assay was validated for bearded reedlings by showing that serial dilutions of plasma (pooled from 5 individuals) ran parallel to the standard curve (Fig. S1). Samples were only analyzed on a single plate, so we could not calculate inter-assay CV specifically for the reedling samples (repeatability of samples was 94.1\%). However, including the plate number as a random factor in the analyses did not change the conclusions.

\section{Statistical analysis}

In total, $n=23$ males and $n=19$ females were sampled. However, we excluded one female from the analyses of the plumage coloration, because we did not succeed in gathering reliable spectral measurements from more than one sample point, which would not be sufficient to provide reliable data for further analyses. We further excluded one male from the analyses of the beard length because the quality of the picture did not allow precise measurements of the beard length.

Statistical analyses were conducted using Statistica 7.1 (Statsoft Inc., Tulsa). All data were tested for normal distribution and no data transformations were required. To test the relationship between the different ornamental features in males and females, we conducted principal component analyses (PCAs) for each sex separately. Therefore, we combined male tail length, beard length, and the spectral variables (brightness and UV chroma), describing the coloration of the head, chin, flank, and back into a PCA. We applied the same procedure to females using tail length and colorimetric variables describing the coloration of the female cheek, chin, and back. We applied "varimax" rotations and normalized the data. The factor scores of the consecutive PCs explaining the highest variation within the chosen variables were extracted using the Kaiser criterion (eigenvalues higher than 1). Based on the findings of the PCA (see "Results" section), we conducted a second PCA on the UV chroma variables of different body parts to produce a single variable representing the structural plumage coloration (males: eigenvalue $=2.62$, variance explained $=87.46 \%$; females: eigenvalue $=1.51$, variance explained $=75.28 \%$ ) for further analyses. We refer to this variable as "overall UV chroma."

We used GLMs to explore the relationship between baseline IGF-1 levels, structural components of the plumage coloration (overall UV chroma), brightness, beard length, and the morphological plumage trait (tail length). Each of these

variables was tested separately, with each plumage trait entering the initial model as dependent variable and IGF-1 being the explanatory variable. Tarsus length and body mass were incorporated as covariates. Since IGF-1 might be linked to the nutritional state of individuals, we also included an interaction between body mass and IGF-1 levels.

Model selection was conducted using stepwise elimination and re-introduction of terms. Starting with the interaction, the non-significant terms were eliminated step by step from the model. Only significant variables were retained in the final model, and each removed variable was re-entered separately into the final model to test their effects (Grafen and Hails 2002; Engqvist 2005; Mahr et al. 2016) (for the list of all models, see Supplementary Material Tables S1-S7). Model assumptions were verified by graphically checking the distribution of residuals. The variance inflation factor was calculated to assess possible multicollinearity, but none was detected. We provide parameter estimates $\pm \mathrm{SE}$ and two-tailed tests throughout.

\section{Results}

\section{Integration of multiple plumage ornaments}

PC1 and PC2 capture the most variation in plumage coloration of the colorimetric variables $(\mathrm{PC} 1$ : eigenvalue $=3.39$, total variance $=56.57 \% ; \mathrm{PC} 2$ : eigenvalue $=1.13$, total variance $=$ $18.86 \%$ ). Brightness of the back loads negatively, whereas UV chroma of the same areas loads strongly positively on PC1, suggesting that high reflectance of structurally based components of the plumage indicates low brightness (Table 1). The three UV chroma variables show very similar loadings. PC2 explains the most variation in the beard length (Table 1), whereas tail length loadings differ from both colorimetric variables and beard length.

Female coloration showed a similar pattern to male coloration: $\mathrm{PC} 1$ (eigenvalue $=1.57$, total variance $=39.3 \%$ ) and PC2 (eigenvalue $=1.18$, total variance $=29.45 \%$ ). Similar to males, the two UV chroma variables show very similar loadings, which is perpendicular to the brightness of the back and opposite from tail length, indicating that brightness of the back and UV chroma of the structural plumage components might

Table 1 Loadings of $\mathrm{PC} 1$ and $\mathrm{PC} 2$ and in male bearded reedlings

\begin{tabular}{lrr}
\hline & \multicolumn{1}{c}{ PC1 } & \multicolumn{1}{c}{ PC2 } \\
\hline Tail length & 0.34 & 0.59 \\
Beard length & -0.24 & 0.79 \\
UV chroma head & 0.89 & 0.17 \\
UV chroma flank & 0.89 & 0.16 \\
UV chroma chin & 0.94 & -0.04 \\
Back brightness & -0.84 & 0.31 \\
\hline
\end{tabular}


be independent traits, whereas tail length is negatively related to brightness in females (Table 2).

\section{Do IGF-1 levels predict plumage colors, tail length, and ornamental patterns?}

Male tail length was positively related to IGF-1 $\left(F_{1,21}=6.65\right.$, $\beta=0.49 \pm 0.19, p=0.02$, Fig. 3a). In contrast, female tail length was not related to IGF-1 or tarsus length (tarsus length: $F_{1,17}=1.65, p=0.22$; IGF-1 levels: $F_{1,17}=0.23, p=0.64$ ). However, after stepwise elimination of non-significant terms and the re-introduction of single terms, a trend, indicating a positive relationship between tail length and body mass, became apparent $\left(F_{1,17}=3.87, p=0.07\right)$.

Beard length was not related to any of the variables measured during the molt (tarsus length: $F_{1,20}=0.51, p=0.48$; body mass: $F_{1,20}=1.36, p=0.26$; IGF-1 levels: $F_{1,20}=0.26$, $p=0.62)$. The brightness of the male back plumage was also unrelated to tarsus length $\left(F_{1,21}=0.003, p=0.95\right)$, body mass $\left(F_{1,21}=0.79, p=0.39\right)$, or IGF-1 levels $\left(F_{1,21}=1.53, p=\right.$ $0.23)$. However, we found a positive relationship between IGF-1 levels and overall UV chroma in males $\left(F_{1,21}=5.09\right.$, $\beta=0.44 \pm 0.19, p=0.03$; Fig. 3b).

In females, the brightness of the back showed a complex relationship with body mass and IGF-1 levels. While increasing levels of IGF-1 were associated with darker coloration in birds with low body mass, heavy birds showed the opposite pattern (body mass: $F_{1,14}=8.90, \beta=-2.89 \pm 0.97, p<0.01$; IGF-1: $F_{1,14}=9.28, \beta=-10.67 \pm 3.5, p<0.01$; body mass * IGF-1 interaction: $F_{1,14}=8.84, \beta=10.06 \pm 3.39, p=0.01$; Fig. S2).

Overall female UV chroma was not related to either IGF-1 $\left(F_{1,16}=0.532, p=0.48\right)$, body mass $\left(F_{1,16}=2.84, p=0.11\right)$, or tarsus length $\left(F_{1,16}=1.78, p=0.20\right)$.

\section{Discussion}

This study provides the first evidence that the IGF-1 signaling pathway may facilitate the development of sexually selected plumage traits in birds. Our results show that in male, but not female, bearded reedlings, IGF-1 levels during molting predict tail length and UV reflectance of the plumage (Fig. 3). Our findings are corroborated by previous studies on bearded reedlings and bring indication that different ornamental features, such as plumage colors and tail length, do not correlate.

Table 2 Loadings of $\mathrm{PC} 1$ and $\mathrm{PC} 2$ in female bearded reedlings

\begin{tabular}{lrr}
\hline & \multicolumn{1}{c}{ PC1 } & \multicolumn{1}{c}{ PC2 } \\
\hline Tail length & 0.15 & -0.76 \\
UV chroma cheek & -0.87 & 0.07 \\
UV chroma chin & -0.85 & -0.07 \\
Brightness back & 0.07 & 0.80 \\
\hline
\end{tabular}
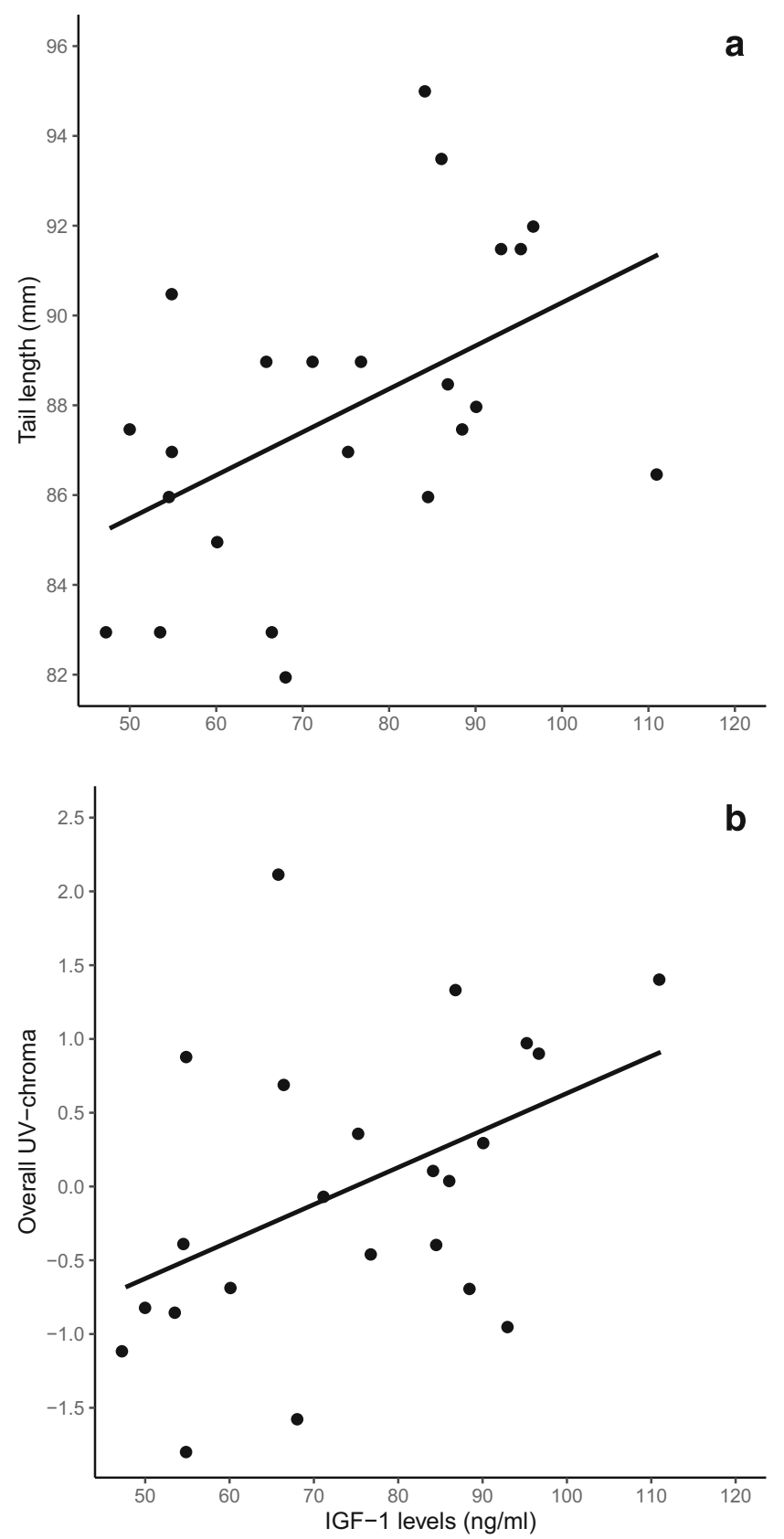

Fig. 3 Baseline IGF-1 levels during molt are related to sexually selected ornaments in male bearded reedlings. Males with higher IGF-1 levels a have longer tails and $\mathbf{b}$ develop plumage with higher reflectance in the UV range

This raises the idea that they either reveal a different set of information (rather than amplifying another signal) or carry no further informational content (Hoi and Griggio 2008; Griggio et al. 2016). Within this context, the question arises how IGF1 can affect the development of ornaments and whether it provides a causal link between body condition and parameters of plumage quality.

Molting is an energy-demanding process, with concomitant major metabolic changes and an increased demand for cell growth, proliferation, and differentiation (Kuenzel 
2003). The corresponding physiological requirements might be an important factor, linking feather development to parameters of individual condition before and during the molt (Murphy et al. 1988; Jovani and Blas 2004; Pap et al. 2008). In white crowned sparrows (Zonotrichia leucophrys gambelii) and house sparrows (Passer domesticus), for example, malnutrition had severe effects on the quality of feathers and the length of flight feathers (Murphy et al. 1988; Pap et al. 2008). In addition, late hatching, late arrival from overwintering sites, and poor body condition often force individuals to increase molt speed to keep pace with conspecifics and to be able to compete for mating partners or resources (Bojarinova et al. 1999). This compensatory measure has negative effects on feather length and plumage quality (Dawson et al. 2000; Vágási et al. 2012). IGF-1 is highly responsive towards the availability of environmental resources, due to its sensitivity to the nutritional status of an individual and to dietary components (e.g., proteins) (Miura et al. 1992; Fontana et al. 2008). It can affect whether energy is allocated into cell proliferation, growth, and protein syntheses (Blumenthal et al. 2011; Dantzer and Swanson 2012; Tighe et al. 2016), which might constitute an important adaptive adjustment to the environmental conditions with long-lasting effects on individual life history (Holzenberger et al. 2003; Dantzer and Swanson 2012; Lewin et al. 2017). The same properties might not only affect growth and life span, as was shown previously (Dantzer and Swanson 2012), but might also have the potential to regulate the allocation of energy into feather growth (Mazzuco et al. 2005). In molting birds, higher individual levels of IGF-1 might stimulate feather development and facilitate the display of more elaborated plumage features. IGF-1 levels were shown to be negatively affected by dietary restrictions (e.g., reduction of the diet and/or protein content) in several vertebrate species, and circulating levels are suggested to play a role in reflecting the nutritional status of cells and regulating energy metabolism (Breier 1999; Regan et al. 2019). Furthermore, IGF-1 promotes protein synthesis in tissues, which might play an important role in the development and growth of plumage, in particular considering the high demand for proteins during feather growth (Murphy and King 1992). Indeed, we show that in bearded reedlings, IGF-1 correlates with male, but not female, tail feather length and UV reflectance. The development of structural plumage components, which are suggested to be responsible for the coloration in the UV range, is complex and requires the regulation of protein synthesis and breakdown of keratin (Hill and McGraw 2006a; Hudson and Wilcoxen 2018). There is strong indication that, similarly to longitudinal growth of feathers, the growth of the regularity of the nanoscaled structures, which cause the reflection in the UV range, is linked to parameters of individual physiological condition during the molt. This was shown in different species; for instance, in blue tits (Cyanistes caeruleus), accelerated molt causes a decrease in the saturation of the UV-blue crown feathers (Griggio et al. 2009). Also, in dark-eyed juncos (Junco hyemalis), the availability of resources (dietary restrictions) during molting negatively affected the growth of structural plumage components (McGlothlin et al. 2007).

In brown-headed cowbirds (Molothrus ater), structural plumage traits, but not melanin-based plumage coloration, were shown to be affected by nutritional stress (McGraw et al. 2002). These findings support our results, which did not reveal a relationship between the measured melaninbased ornamental features (beard length and brightness of the back), IGF-1 levels, body mass, or tarsus length. This is particularly interesting because the beard of male bearded reedlings is a melanin-based plumage ornament, which underlies strong sexual selection processes. Males with longer beards are more dominant, and females clearly display a preference for them as potential mates (Hoi and Griggio 2008, 2012; Griggio et al. 2016). These characteristics raise the idea that the beard might be costly to produce and serves as an honest indicator of quality (Andersson 1994b; Hoi and Griggio 2008; Griggio et al. 2016). Indeed, the degree of melanization and the size of some types of melanin-based ornaments can be sensitive towards environmental factors and dietary components and hence serve as potential indicators of condition during the molt (Jawor and Breitwisch 2003; Roulin 2004; Musgrove and Wiebe 2016; Roulin 2016), but this idea remains controversial as the costs of melanin-based plumage ornaments are yet not well understood (McGraw et al. 2002; McGraw 2008; Guindre-Parker and Love 2014). One example, which resembles the beard length of the male bearded reedling, is the black throat badge of the male house sparrow (Passer domesticus). It is a melanin-based ornament which is considered to serve as an honest signal and indicates dominance to conspecifics, but its size was not affected during a dietary restriction experiment by McGraw et al. (2002) and McGraw (2008). Similar findings in great tits (Parus major) also suggest that the black breast band was not affected by nutritional condition (Senar et al. 2003). Whereas the growth and the development of feather structures require high amounts of proteins, the degree of melanization is not necessarily dependent on the availability of these energy resources. The modulation of melanin pigmentation is most likely connected to genetic prerequisites and other physiological constraints, such as, for example, the availability of certain elements and amino acids, and further might underlie the regulation of androgen levels (Senar et al. 2003; McGraw 2008; Roulin 2016). However, we did not measure the exact type and ratio of the specific pigment types in our study. Melanin-based plumage colors result from two specific types of melanin pigments, namely eu- and phaeomelanin, which differ substantially in their regulation and costs (Hill and McGraw 2006a, b; Roulin 2016). We suggest that future investigations should consider these differences. 
In female bearded reedlings, neither of the ornamental features were significantly correlated with IGF-1 levels. This is particularly surprising, because tail length underlies mutual mate choice in bearded reedlings and we found a weak correlation between tail length and body mass, which corresponds with the idea that it serves as a potential indicator of quality (Romero-Pujante et al. 2002). Interestingly, our study indicates that dependent on the body mass, IGF-1 might positively affect the melanin pigmentation of the brown back in females, whereas no such relationship became apparent in males. Heavier females with lower IGF-1 and smaller females with high IGF-1 displayed darker back plumage than heavy birds with high IGF-1 or light birds with low IGF-1. One possible explanation is that this effect is due to different selection pressures acting on males and females (Romero-Pujante et al. 2002). We cannot rule out that IGF-1 might have effects, which facilitate the growth of more pigmented feathers in females, but it should be considered that overall, our study did not reveal a significant relationship between body mass or size during the molt and any of the plumage ornaments in both sexes. However, we obtained only one measure of body condition and molting birds undergo an energetic demanding period, which was previously demonstrated to significantly affect parameters of body condition. Muscle score, body fat, and mass in molting birds are often low (Dolnik and Valery 1979; Swaddle and Witter 1997; Minias et al. 2010) which may explain why we did not find a relationship between body mass and the ornamental features.

Overall, our study is the first to report a relationship between IGF-1 levels during molting and the elaboration of ornamental feather traits and colors in adult birds. The distinct properties of IGF-1, namely its sensitivity towards nutrition and its important role in the mechanisms stimulating growth and development, make it a potential candidate to further investigate the mechanisms linking parameters of individual condition and the capacity to display elaborated ornaments.

Acknowledgments We thank S. Wiedermann and A. Nurmisto for their support during the data collection, R. Hengsberger for copyediting the manuscript, and G. Rédai for painting Fig. 1. We further thank the Nationalpark Neusiedlersee for access to the study population and hosting our project during the fieldwork. We also thank the anonymous reviewers, who provided constructive comments on an earlier version of the manuscript.

Author contribution AZL, HH, OV, and KM designed the study; OV, $\mathrm{KM}$, and ZT conducted the experiment and took samples and measurements; AZL and ZT conducted the lab analysis; KM and AZL conducted statistical analyses; and KM and AZL wrote the manuscript with significant contributions from OV, ZT, and HH. All of the authors read and approved the final manuscript.

Funding Information Open access funding provided by University of Veterinary Medicine Vienna. Funding was provided by the Hungarian National Development, Research and Innovation Office (NKFIH) (OTKA K113108) and by a bilateral research grant of the NKFIH (TÉT
15-1-2016-0044) and the Österreichischer Austauschdienst (ÖAD, WTZ \#HU 02/2016). KM was supported by a Schrödinger fellowship (\# J4235B29) granted by the FWF. AZL and ZT were supported by a grant from the European Union and the European Social Fund (EFOP-3.6.1-162016-00022) and AZL by the Romanian Ministry of Education (PN-IIIP4-ID-PCE-2016-0572). OV was supported by the Hungarian Eötvös Scholarship (MÁEÖ2016_15/76740), the "János Bolyai Research Scholarship of the Hungarian Academy of Sciences," and by an Exploratory Research Grant of the Romanian Ministry of Research and Innovation (PN-III-P4-ID-PCE-2016-0404).

Data availability Data is available as supplementary material.

\section{Compliance with ethical standards}

Conflict of interest The authors declare that they have no conflict of interest.

Ethical approval We followed all applicable international, national, and institutional guidelines for the use of animals. All procedures performed in studies involving animals were in accordance with the ethical standards of the institution and approved by the Austrian Federal Ministry of Education, Science and Research ( $\$ 26$ of the Law for Animal Experiments, Tierversuchsgesetz 2012-TG 2012, permit number: GZBMWF-68.205/0012-WF/V/3b/2017).

Open Access This article is licensed under a Creative Commons Attribution 4.0 International License, which permits use, sharing, adaptation, distribution and reproduction in any medium or format, as long as you give appropriate credit to the original author(s) and the source, provide a link to the Creative Commons licence, and indicate if changes were made. The images or other third party material in this article are included in the article's Creative Commons licence, unless indicated otherwise in a credit line to the material. If material is not included in the article's Creative Commons licence and your intended use is not permitted by statutory regulation or exceeds the permitted use, you will need to obtain permission directly from the copyright holder. To view a copy of this licence, visit http://creativecommons.org/licenses/by/4.0/.

\section{References}

Alonso ME, Pérez JA, Gaudioso VR, Diéz C, Prieto R (2005) Study of survival, dispersal and home range of autumn-released red-legged partridges (Alectoris rufa). Br Poultry Sci 46:401-406. https://doi. org $/ 10.1080 / 00071660500180968$

Alonso-Alvarez C (2001) Effects of testosterone implants on pair behaviour during incubation in the yellow-legged gull Larus cachinnans. J Avian Biol 32:326-332. https://doi.org/10.1111/j.0908-8857.2001. 320406.x

Andersson MB (1994a) Sexual selection. Princeton University Press, Princeton, NJ

Andersson S (1994b) Costs of sexual advertising in the lekking Jackson's widowbird. Condor 96:1-10. https://doi.org/10.2307/1369058

Andersson S, Pryke SR, Örnborg J, Lawes MJ, Andersson M (2002) Multiple receivers, multiple ornaments, and a trade-off between agonistic and epigamic signaling in a widowbird. Am Nat 160:683691. https://doi.org/10.1086/342817

Andrew RJ (1969) The effects of testosterone on avian vocalizations. In: Hinde R (ed) Bird vocalizations their relation to current problems in biology and psychology. Cambridge University Press, London, pp 97-130 
Barbieri M, Bonafe M, Franceschi C, Paolisso G (2003) Insulin/IGF-Isignaling pathway: an evolutionarily conserved mechanism of longevity from yeast to humans. Am J Physiol-Endocrinol Metab 285: E1064-E1071. https://doi.org/10.1152/ajpendo.00296.2003

Bartke A, Chandrashekar V, Dominici F, Turyn D, Kinney B, Steger R, Kopchick JJ (2003) Insulin-like growth factor 1 (IGF-1) and aging: controversies and new insights. Biogerontology 4:1-8. https://doi. org/10.1023/A:1022448532248

Beccavin C, Chevalier B, Cogburn LA, Simon J, Duclos MJ (2001) Insulin-like growth factors and body growth in chickens divergently selected for high or low growth rate. J Endocrinol 168:297-306. https://doi.org/10.1677/joe.0.1680297

Blumenthal S, Morgan-Boyd R, Nelson R, Garshelis DL, Turyk ME, Unterman $T$ (2011) Seasonal regulation of the growth hormoneinsulin-like growth factor-I axis in the American black bear (Ursus americanus). Am J Physiol-Endocrinol Metab 301:E628-E636. https://doi.org/10.1152/ajpendo.00082.2011

Bojarinova JG, Lehikoinen E, Eeva T (1999) Dependance of postjuvenile moult on hatching date, condition and sex in the great tit. J Avian Biol 30:437-446. https://doi.org/10.2307/3677016

Breier BH (1999) Regulation of protein and energy metabolism by the somatotropic axis. Domest Anim Endocrin 17:209-218. https://doi. org/10.1016/S0739-7240(99)00038-7

Candolin U (2003) The use of multiple cues in mate choice. Biol Rev 78: 575-595. https://doi.org/10.1017/S1464793103006158

Ciucci F, Putignano E, Baroncelli L, Landi S, Berardi N, Maffei L (2007) Insulin-like growth factor 1 (IGF-1) mediates the effects of enriched environment (EE) on visual cortical development. PLoS One 2: e475. https://doi.org/10.1371/journal.pone.0000475

Clemmons DR (2012) Metabolic actions of IGF-I in normal physiology and diabetes. Endocrinol Metab Clin 41:425-443. https://doi.org/ 10.1016/j.ecl.2012.04.017

Dantzer B, Swanson EM (2012) Mediation of vertebrate life histories via insulin-like growth factor-1. Biol Rev 87:414 429. https://doi.org/ 10.1111/j.1469-185X.2011.00204.x

Dawson A, Hinsley SA, Ferns PN, Bonser RHC, Eccleston L (2000) Rate of moult affects feather quality: a mechanism linking current reproductive effort to future survival. Proc R Soc Lond B 267:20932098. https://doi.org/10.1098/rspb.2000.1254

Delhey K, Kempenaers B (2006) Age differences in blue tit Parus caeruleus plumage colour: within-individual changes or colourbiased survival? J Avian Biol 37:339-348. https://doi.org/10.1111/ j.2006.0908-8857.03655.x

Ditchkoff SS, Spicer LJ, Masters RE, Lochmiller RL (2001) Concentrations of insulin-like growth factor-I in adult male whitetailed deer (Odocoileus virginianus): associations with serum testosterone, morphometrics and age during and after the breeding season. Comp Biochem Physiol A 129:887-895. https://doi.org/10.1016/ S1095-6433(01)00351-8

Dolnik VR, Valery MG (1979) Bioenergetics of molt in the chaffinch (Fringilla coelebs). Auk 96:253-264 http://www.jstor.org/stable/ 4085306

Doublier S, Duyckaerts C, Seurin D, Binoux M (2000) Impaired brain development and hydrocephalus in a line of transgenic mice with liver-specific expression of human insulin-like growth factor binding protein-1. Growth Hormon IGF Res 10:267-724. https://doi.org/ 10.1054/ghir.2000.0168

Emlen DJ, Warren IA, Johns A, Dworkin I, Lavine LC (2012) A mechanism of extreme growth and reliable signaling in sexually selected ornaments and weapons. Science 337:860-864. https://doi.org/10. 1126/science. 1224286

Engqvist L (2005) The mistreatment of covariate interaction terms in linear model analyses of behavioural and evolutionary ecology studies. Anim Behav 70:967-971. https://doi.org/10.1016/j.anbehav. 2005.01.016
Flatt T, Heyland A (eds) (2011) Mechanisms of life history evolution: the genetics and physiology of life history traits and trade-offs. Oxford University Press, Oxford

Fontana L, Weiss EP, Villareal DT, Klein S, Holloszy JO (2008) Longterm effects of calorie or protein restriction on serum IGF-1 and IGFBP-3 concentration in humans. Aging Cell 7:681-687. https:// doi.org/10.1111/j.1474-9726.2008.00417.x

Gabillard JC, Weil C, Rescan PY, Navarro I, Gutiérrez J, Le Bail PY (2003) Effects of environmental temperature on IGF1, IGF2, and IGF type I receptor expression in rainbow trout (Oncorhynchus mykiss). Gen Comp Endocr 133:233-242. https://doi.org/10.1016/ S0016-6480(03)00167-9

Grafen A, Hails R (2002) Modern statistics for the life sciences. Learn to analyse your own data. Oxford University Press, Oxford

Griggio M, Serra L, Licheri D, Campomori C, Pilastro A (2009) Moult speed affects structural feather ornaments in the blue tit. J Evol Biol 22:782-792. https://doi.org/10.1111/j.1420-9101.2009.01700.x

Griggio M, Hoi H, Pilastro A (2010a) Plumage maintenance affects ultraviolet colour and female preference in the budgerigar. Behav Process 84:739-744. https://doi.org/10.1016/j.beproc.2010.05.003

Griggio M, Zanollo V, Hoi H (2010b) UV plumage color is an honest signal of quality in male budgerigars. Ecol Res 25:77-82. https:// doi.org/10.1007/s11284-009-0632-3

Griggio M, Hoi H, Lukasch B, Pilastro A (2016) Context-dependent female preference for multiple ornaments in the bearded reedling. Ecol Evol 6:493-501. https://doi.org/10.1002/ece3.1903

Guindre-Parker S, Love OP (2014) Revisiting the condition-dependence of melanin-based plumage. J Avian Biol 45:29-33. https://doi.org/ 10.1111/j.1600-048X.2013.00190.x

Gunnell D, Oliver SE, Peters TJ, Donovan JL, Persad R, Maynard M, Gillatt D, Pearce A, Hamdy FC, Neal DE, Holly JM (2003) Are dietprostate cancer associations mediated by the IGF axis? A crosssectional analysis of diet, IGF-I and IGFBP-3 in healthy middleaged men. Brit J Cancer 88:1682-1686. https://doi.org/10.1038/sj. bjc.6600946

Harshman LG, Zera AJ (2007) The cost of reproduction: the devil in the details. Trends Ecol Evol 22:80-86. https://doi.org/10.1016/j.tcb. 2007.04.001

Hau M (2007) Regulation of male traits by testosterone: implications for the evolution of vertebrate life histories. BioEssays 29:133-144. https://doi.org/10.1002/bies.20524

Hill GE, McGraw KJ (2006a) Bird coloration - function and evolution, vol 2. Harvard University Press, Cambridge

Hill GE, McGraw KJ (2006b) Bird coloration - mechanisms and measurements. Harvard University Press, Cambridge

Hoi H, Griggio M (2008) Dual utility of a melanin-based ornament in bearded tits. Ethology 114:1094-1100. https://doi.org/10.1111/j. 1439-0310.2008.01566.x

Hoi H, Griggio M (2012) Bearded reedlings adjust their pair-bond behaviour in relation to the sex and attractiveness of unpaired conspecifics. PLoS One 7:e32806. https://doi.org/10.1371/journal.pone.0032806

Holzenberger M, Dupont J, Ducos B, Leneuve P, Géloën A, Even PC, Cervera P, Le Bouc Y (2003) IGF-1 receptor regulates lifespan and resistance to oxidative stress in mice. Nature 421:182-187. https:// doi.org/10.1038/nature01298

Hudson SB, Wilcoxen TE (2018) Condition dependence of structural plumage coverage in indigo buntings Passerina cyanea. Avian Biol Res 11:54-61. https://doi.org/10.3184/ $175815617 \times 15063340995383$

Jacot A, Kempenaers B (2006) Condition-dependent expression of UVplumage traits in blue tits. J Ornithol 147:62 (abstract)-297. https:// doi.org/10.1007/s10336-006-0093-1

Jawor JM, Breitwisch R (2003) Melanin ornaments, honesty, and sexual selection. Auk 120:249-265. https://doi.org/10.1642/00048038(2003)120[0249:MOHASS]2.0.CO;2 
Jovani R, Blas J (2004) Adaptive allocation of stress-induced deformities on bird feathers. J Evol Biol 17:294-301. https://doi.org/10.1111/j. 1420-9101.2003.00680.x

Ketterson ED, Nolan V Jr (1999) Adaptation, exaptation, and constraint: a hormonal perspective. Am Nat 154:S4-S25. https://doi.org/10. $1086 / 303280$

Keyser AJ, Hill GE (1999) Condition-dependent variation in the blueultraviolet coloration of a structurally based plumage ornament. Proc R Soc Lond B 266:771-777. https://doi.org/10.1098/rspb.1999. 0704

Kuenzel WJ (2003) Neurobiology of molt in avian species. Poultry Sci 82:981-991. https://doi.org/10.1093/ps/82.6.981

LaFountain AM, Prum RO, Frank HA (2015) Diversity, physiology, and evolution of avian plumage carotenoids and the role of carotenoidprotein interactions in plumage color appearance. Arch Biochem Biophys 572:201-212. https://doi.org/10.1016/j.abb.2015.01.016

Laucht S, Dale J (2012) Correlations of condition, testosterone, and age with multiple ornaments in male house sparrows: patterns and implications. Condor 114:865-873. https://doi.org/10.1525/cond. 2012.110194

Lewin N, Swanson EM, Williams BL, Holekamp KE (2017) Juvenile concentrations of IGF-1 predict life-history trade-offs in a wild mammal. Funct Ecol 31:894-902. https://doi.org/10.1111/13652435.12808

Liu JP, Baker J, Perkins AS, Robertson EJ, Efstratiadis A (1993) Mice carrying null mutations of the genes encoding insulin-like growth factor I (Igf-1) and type 1 IGF receptor (Igflr). Cell 75:59-72. https:// doi.org/10.1016/S0092-8674(05)80084-4

Lodjak J, Mägi M, Tilgar V (2014) Insulin-like growth factor 1 and growth rate in nestlings of a wild passerine bird. Funct Ecol 28: 159-166. https://doi.org/10.1111/1365-2435.12164

Lodjak J, Tilgar V, Mägi M (2016) Does the interaction between glucocorticoids and insulin-like growth factor 1 predict nestling fitness in a wild passerine? Gen Comp Endocrinol 225:149-154. https://doi. org/10.1016/j.ygcen.2015.10.016

Lodjak J, Mägi M, Sild E, Mänd R (2017) Causal link between insulinlike growth factor 1 and growth in nestlings of a wild passerine bird. Funct Ecol 31:184-191. https://doi.org/10.1111/1365-2435.12679

Loyau A, Saint Jalme M, Cagniant C, Sorci G (2005) Multiple sexual advertisements honestly reflect health status in peacocks (Pavo cristatus). Behav Ecol Sociobiol 58:552-557. https://doi.org/10. 1007/s00265-005-0958-y

Mahr K, Griggio M, Granatiero M, Hoi H (2012) Female attractiveness affects paternal investment: experimental evidence for male differential allocation in blue tits. Front Zool 9:14. https://doi.org/10. 1186/1742-9994-9-14

Mahr K, Evans C, Thonhauser KE, Griggio M, Hoi H (2016) Multiple ornaments - multiple signaling functions? The importance of song and UV plumage coloration in female superb fairy wrens (Malurus cyaneus). Front Ecol Evol 4:43. https://doi.org/10.3389/fevo.2016. 00043

Mattson MP, Maudsley S, Martin B (2004) A neural signaling triumvirate that influences ageing and age-related disease: insulin/IGF-1, BDNF and serotonin. Ageing Res Rev 3:445-464. https://doi.org/10.1016/ j.arr.2004.08.001

Mays HL Jr, McGraw KJ, Ritchison G, Cooper S, Rush VN, Parker RS (2004) Sexual dichromatism in the yellow-breasted chat Icteria virens: spectrophotometric analysis and biochemical basis. J Avian Biol 35:125-134. https://doi.org/10.1111/j.0908-8857.2004.03101. $\mathrm{x}$

Mazzuco H, McMurtry JP, Kuo AY, Hester P (2005) The effect of preand postmolt diets high in n-3 fatty acids and molt programs on skeletal integrity and insulin-like growth factor-I of white leghorns. Poultry Sci 84:1735-1749. https://doi.org/10.1093/ps/84.11.1735

McGlothlin JW, Duffy DL, Henry-Freeman JL, Ketterson ED (2007) Diet quality affects an attractive white plumage pattern in dark-eyed juncos (Junco hyemalis). Behav Ecol Sociobiol 61:1391-1399. https://doi.org/10.1007/s00265-007-0370-x

McGraw KJ (2008) An update on the honesty of melanin-based color signals in birds. Pigm Cell Melanoma Res 21:133-138. https://doi. org/10.1111/j.1755-148X.2008.00454.x

McGraw KJ, Mackillop EA, Dale J, Hauber ME (2002) Different colors reveal different information: how nutritional stress affects the expression of melanin- and structurally based ornamental plumage. J Exp Biol 205:3747-3755 http://jeb.biologists.org/content/205/23/ 3747.long

McGraw KJ, Safran RJ, Wakamatsu K (2005) How feather colour reflect its melanin content. Funct Ecol 19:816-821. https://doi.org/10.1111/ j.1365-2435.2005.01032.x

McMurtry JP, Francis GL, Upton Z (1997) Insulin-like growth factors in poultry. Domest Anim Endocrin 14:199-229. https://doi.org/10. 1016/S0739-7240(97)00019-2

Minias P, Kaczmarek K, Włodarczyk R, Janiszewski T (2010) Adjustments and exploitation of body stores during post-juvenile molt in common snipe Gallinago gallinago. Waterbirds 33:116120. https://doi.org/10.1675/063.033.0115

Miura Y, Kato H, Noguchi T (1992) Effect of dietary proteins on insulinlike growth factor-1 (IGF-1) messenger ribonucleic acid content in rat liver. Br J Nutr 67:257-265. https://doi.org/10.1079/ BJN19920029

Murphy ME, King JR (1992) Energy and nutrient use during moult by white-crowned sparrows Zonotrichia leucophrys gambelii. Ornis Scand 23:304-313. https://doi.org/10.2307/3676654

Murphy TG, Pham TT (2012) Condition and brightness of structural blue-green: motmot tail-racket brightness is related to speed of feather growth in males, but not in females. Biol J Linn Soc 106:673681. https://doi.org/10.1111/j.1095-8312.2012.01891.x

Murphy ME, King JR, Lu J (1988) Malnutrition during the postnuptial molt of white-crowned sparrows: feather growth and quality. Can J Zool 66:1403-1413. https://doi.org/10.1139/z88-206

Musgrove AB, Wiebe KL (2016) Condition-dependent expression of carotenoid- and melanin-based plumage colour of northern flicker nestlings revealed by manipulation of brood size. J Avian Biol 47: 176-184. https://doi.org/10.1111/jav.00730

Nolan V Jr, Ketterson ED, Ziegenfus C, Cullen DP, Chandler CR (1992) Testosterone and avian life histories: effects of experimentally elevated testosterone on prebasic molt and survival in male dark-eyed juncos. Condor 94:364-370. https://doi.org/10.2307/1369209

Ornelas JF, González C, de los Monteros AE (2009) Uncorrelated evolution between vocal and plumage coloration traits in the trogons: a comparative study. J Evol Biol 22:471-484. https://doi.org/10.1111/ j.1420-9101.2008.01679.x

Osorio D, Ham AD (2002) Spectral reflectance and directional properties of structural coloration in bird plumage. J Exp Biol 205:2017-2027 https://jeb.biologists.org/content/205/14/2017

Pap PL, Vágási CI, Czirják GÁ, Barta Z (2008) Diet quality affects postnuptial molting and feather quality of the house sparrow (Passer domesticus): interaction with humoral immune function? Can J Zool 86:834-842. https://doi.org/10.1139/Z08-060

Peiró IG, Robledano F, Esteve MA (2006) The effect of age and sex on wing morphology and body size of the bearded tit Panurus biarmicus in relation to complete moult. Ringing Migr 23:101106. https://doi.org/10.1080/03078698.2006.9674352

Peters A, Delhey K, Goymann W, Kempenaers B (2006) Age-dependent association between testosterone and crown UV coloration in male blue tits (Parus caeruleus). Behav Ecol Sociobiol 59:666-673. https://doi.org/10.1007/s00265-005-0095-7

Regan JC, Froy H, Walling CA, Moatt JP, Nussey DH (2019) Dietary restriction and insulin-like signalling pathways as adaptive plasticity: a synthesis and re-evaluation. Funct Ecol 34:107-128. https:// doi.org/10.1111/1365-2435.13418 
Roberts ML, Ras E, Peters A (2009) Testosterone increases UV reflectance of sexually selected crown plumage in male blue tits. Behav Ecol 20:535-541. https://doi.org/10.1093/beheco/arp028

Romero LM, Reed JM (2005) Collecting baseline corticosterone samples in the field: is under 3 min good enough? Comp Biochem Physiol A 140:73-79. https://doi.org/10.1016/j.cbpb.2004.11.004

Romero-Pujante M, Hoi H, Blomqvist D, Valera F (2002) Tail length and mutual mate choice in bearded tits (Panurus biarmicus). Ethology 108:885-895. https://doi.org/10.1046/j.1439-0310.2002.00821.x

Roulin A (2004) Proximate basis of the covariation between a melaninbased female ornament and offspring quality. Oecologia 140:668675. https://doi.org/10.1007/s00442-004-1636-x

Roulin A (2016) Condition-dependence, pleiotropy and the handicap principle of sexual selection in melanin-based colouration. Biol Rev 91:328-348. https://doi.org/10.1111/brv.12171

Rueden CT, Schindelin J, Hiner MC, DeZonia BE, Walter AE, Arena ET, Eliceiri KW (2017) ImageJ2: ImageJ for the next generation of scientific image data. BMC Bioinform 18:529. https://doi.org/10. 1186/s12859-017-1934-z

Senar JC, Figuerola J, Domènech J (2003) Plumage coloration and nutritional condition in the great tit Parus major: the roles of carotenoids and melanins differ. Naturwissenschaften 90:234-237. https://doi. org/10.1007/s00114-003-0414-7

Shawkey MD, Hill GE (2005) Carotenoids need structural colours to shine. Biol Lett 1:121-124. https://doi.org/10.1098/rsbl.2004.0289

Shit N, Sastry KVH, Singh RP, Pandey NK, Mohan J (2014) Sexual maturation, serum steroid concentrations, and mRNA expression of IGF-1, luteinizing and progesterone hormone receptors and survivin gene in Japanese quail hens. Theriogenology 81:662-668. https://doi.org/10.1016/j.theriogenology.2013.12.011

Sparkman AM, Vleck CM, Bronikowski AM (2009) Evolutionary ecology of endocrine-mediated life-history variation in the garter snake Thamnophis elegans. Ecology 90:720-728. https://doi.org/10.1890/ 08-0850.1

Surmacki A, Stepniewski J, Stepniewska M (2015) Juvenile sexual dimorphism, dichromatism and condition-dependent signaling in a bird species with early pair bonds. J Ornithol 156:65-73. https:// doi.org/10.1007/s10336-014-1108-y
Suttie JM, Gluckman PD, Butler JH, Fennessy PF, Corson ID, Laas FJ (1985) Insulin-like growth factor-I (IGF-1) antler-stimulating hormone. Endocrinology 116:846-848. https://doi.org/10.1210/endo116-2-846

Svensson L (1992) Identification guide to European passerines, 4th rev. edn. British Trust for Ornithology, Thetford

Svensson E, Merilä J (1996) Molt and migratory condition in blue tits: a serological study. Condor 98:825-831. https://doi.org/10.2307/ 1369863

Swaddle JP, Witter MS (1997) The effects of molt on the flight performance, body mass, and behavior of European starlings (Sturnus vulgaris): an experimental approach. Can J Zool 75:1135-1146. https://doi.org/10.1139/z97-136

Tighe RL, Bonde RK, Avery JP (2016) Seasonal response of ghrelin, growth hormone, and insulin-like growth factor I in the freeranging Florida manatee (Trichechus manatus latirostris). Mamm Biol 81:247-254. https://doi.org/10.1016/j.mambio.2016.02.006

Tóth Z, Ouyang JQ, Lendvai ÁZ (2018) Exploring the mechanistic link between corticosterone and insulin-like growth factor-1 in a wild passerine bird. PeerJ 6:e5936. https://doi.org/10.7717/peerj.5936

Vágási CI, Pap PL, Vincze O, Benkő Z, Marton A, Barta Z (2012) Haste makes waste but condition matters: molt rate-feather quality tradeoff in a sedentary songbird. PLoS One 7:e40651. https://doi.org/10. 1371/journal.pone.0040651

Wingfield JC, Romero LM (2001) Adrenocortical responses to stress and their modulation in free-living vertebrates. In: Pollock DM (ed) Comprehensive physiology. Supplement 23. Handbook of physiology, the endocrine system, coping with the environment: neural and endocrine mechanisms. Wiley, Hoboken, pp 221-234

Zera AJ, Harshman LG (2001) The physiology of life history trade-offs in animals. Annu Rev Ecol Syst 32:95-126. https://doi.org/10.1146/ annurev.ecolsys.32.081501.114006

Publisher's note Springer Nature remains neutral with regard to jurisdictional claims in published maps and institutional affiliations. 